Original Research Article

\title{
Evaluation of anxiolytic effect of furosemide in Albino rats
}

\author{
Malvika Goyal, Jyothi C. H.*, Rahul H. Damodar
}

Department of Pharmacology, JJM Medical College, Davangere, Karnataka, India

Received: 19 November 2017 Accepted: 28 December 2017

\section{*Correspondence to:}

Dr. Jyothi C. H.,

Email: drjyothich@gmail.com

Copyright: (C) the author(s), publisher and licensee Medip Academy. This is an openaccess article distributed under the terms of the Creative Commons Attribution NonCommercial License, which permits unrestricted noncommercial use, distribution, and reproduction in any medium, provided the original work is properly cited.

\begin{abstract}
Background: Anxiety disorders are the most prevalent class of psychiatric condition. Medications commonly given for treatment can elicit several central nervous system (CNS) side-effects that patients find difficult to tolerate. So there is a need for new pharmacotherapeutic approaches to treat anxiety with greater efficacy and fewer side effects. Hence this study has been taken up to evaluate the anxiolytic effect of furosemide at three different doses $(75 \mathrm{mg} / \mathrm{kg}, 150 \mathrm{mg} / \mathrm{kg}$ and $200 \mathrm{mg} / \mathrm{kg}$ ) in Albino rats.
\end{abstract}

Methods: After obtaining approval from the institutional animal ethical committee 30 Albino rats weighing about 150-200gm were taken and divided into 5 groups of 6 rats each. Group 1: Normal Saline 10ml/kg (control); Group 2: Diazepam 2mg/kg (standard); Group 3: Furosemide $150 \mathrm{mg} / \mathrm{kg}$ (test group 1); Group 4: Furosemide 200mg/kg (test group 2); Group 5: Furosemide 75mg/kg + Diazepam $1 \mathrm{mg} / \mathrm{kg}$ (sub threshold dose). The anxiolytic activity of furosemide was tested by elevated plus maze and digital actophotometer models. Data was analysed using one way ANOVA followed by Posthoc Tukey's test.

Results: Furosemide $(150 \mathrm{mg} / \mathrm{kg}$ and $200 \mathrm{mg} / \mathrm{kg}$ ) have shown significant increase in open arm entries $(\mathrm{p}<0.05)$ and time spent in open arm $(\mathrm{p}<0.05)$ compared to control. Also furosemide $(150 \mathrm{mg} / \mathrm{kg}$ and $200 \mathrm{mg} / \mathrm{kg}$ ) have shown statistically significant decrease in locomotor activity $(p<0.05)$ compared to control in actophotometer model. Potentiation of time spent and number of entries in open arm and decrease in locomotor activity were noticed when sub threshold doses of combination of diazepam and furosemide were used.

Conclusions: These results suggest that furosemide possesses significant anxiolytic activity at both the doses. Furosemide given in sub threshold dose potentiates the antianxiety effect of sub threshold dose of diazepam when used in combination. Hence, after further studies, furosemide can be used as an anxiolytic drug.

Keywords: Anxiety disorders, Actophotometer, Elevated plus maze, Furosemide

\section{INTRODUCTION}

Anxiety disorders are the most prevalent class of psychiatric condition affecting about $3.8-25 \%^{2}$ of the world's population. ${ }^{1}$ Anxiety is an emotion characterized by feeling of tension, worried thoughts and physical changes like increased blood pressure. People with anxiety disorders usually have recurring intrusive thoughts or concerns. They may also have physical symptoms such as sweating, trembling, dizziness or tachycardia. ${ }^{2}$
There are several types of anxiety disorders amongst which generalised anxiety disorder (GAD) is the most common. Other disorders include panic disorder, social anxiety disorder, posttraumatic stress disorder and specific phobia. $^{3}$

Medications currently used in treatment of these disorders include tricyclic antidepressants, selective serotonin reuptake inhibitors (SSRIs), serotonin norepinephrine reuptake inhibitors (SNRIs), benzodiazepines, anticonvulsants, and monoamine oxidase inhibitors. ${ }^{3}$ 
Among them Benzodiazepines are the major class of compounds used in anxiety and they have remained the most commonly prescribed treatment for anxiety, despite the important unwanted side effects such as sedation, muscle relaxation, ataxia and amnesia. ${ }^{4}$ However, $20 \%$ $40 \%$ of anxiety patients remain non-responders to all available therapies. Additionally, many of the anxiolytic medications can elicit central nervous system (CNS) sideeffects that patients find difficult to tolerate. ${ }^{3}$ So there is a need for new pharmacotherapeutic approaches to treat anxiety with greater efficacy and fewer side effects. ${ }^{4}$

Studies and hypothesis have suggested the role of various neurotransmitters like GABA and serotonin in the pathophysiology of anxiety. ${ }^{3}$ The downregulation of $\mathrm{GABA}_{\mathrm{A}}$ inhibition in the brain has been hypothesized to contribute to pathophysiology of anxiety. The probable mechanism of anxiolytic properties of Furosemide could be by enhancing GABA inhibition, causing antagonism of $\mathrm{Na}^{+}-\mathrm{K}^{+}-2 \mathrm{CL}^{-}$and $\mathrm{Na}^{+}-\mathrm{CL}^{-}$cotransporters. ${ }^{5-10}$ Further studies are required to explore the exact mechanism of action of anxiolytic effect of furosemide.

Loop diuretics are presently use for cardiovascular conditions like hypertension and congestive cardiac failure. There is increased prevalence of anxiety in these patients which contributes to morbidity and mortality. ${ }^{11}$ Hence this study is undertaken to evaluate the anti-anxiety effects of furosemide.

\section{METHODS}

The study was initiated after seeking the necessary approval from the Institutional Ethics Committee, JJM Medical College in accordance with CPCSEA (Committee for the Purpose of Control and Supervision of Experiments on Animals, India). The duration of study is 18 months.

\section{Drugs and chemicals}

Normal saline: $10 \mathrm{ml} / \mathrm{kg}$, Diazepam: $1 \mathrm{mg} / \mathrm{kg}, 2 \mathrm{mg} / \mathrm{kg}$, Furosemide: $75 \mathrm{mg} / \mathrm{kg}, 150 \mathrm{mg} / \mathrm{kg}, 200 \mathrm{mg} / \mathrm{kg}$. All drugs were given intra-peritoneally (I.P) and administered 30 minutes prior to testing.

\section{Selection of animals}

A total of 30 Albino rats of either sex, weighing around 200-250g was obtained from animal house of JJM Medical College. The animals had free access to food and water and was maintained under standard conditions of temperature, humidity, and light (12h light/ $12 \mathrm{~h}$ dark cycle). Healthy Albino rats weighing 200-250g with normal behaviour and activity were included in this study. The rats previously unused for any experiment were taken. Pregnant and diseased animals were excluded.

Albino rats of either sex, weighing around 200-250g were randomly selected. All the animals were kept under laboratory condition for acclimatization period of seven days before carrying out the experiments. Each rat was housed separately in a metallic cage and provided with adequate food and water. They were maintained under standard laboratory conditions with natural light and dark cycle, under room temperature. The animals were divided into five groups of six rats each.

The drugs were administered as shown below:

- Group I - Control rats (normal saline $10 \mathrm{ml} / \mathrm{kg})(\mathrm{C})$

- Group II - Standard (diazepam $2 \mathrm{mg} / \mathrm{kg})(\mathrm{S})$

- Group III - Furosemide $(150 \mathrm{mg} / \mathrm{kg})(\mathrm{T} 1)$

- Group IV - Furosemide (200mg/kg)(T2)

- Group V - Furosemide and Diazepam (75mg/kg+ $1 \mathrm{mg} / \mathrm{kg})(\mathrm{T} 3)$

Anxiolytic effects of furosemide were tested on two standard rat anxiety models:

- Elevated Plus Maze

- Digital Actophotometer.

\section{Elevated Plus Maze (EPM)}

\section{Principle}

This model is based on natural behaviour of rodents for open spaces and fear of height. Generally rodents tend to avoid the open areas and stay in darker areas, more enclosed spaces. When animal is placed on EPM anxious animals spend more time in enclosed arms and nonanxious animals explore and spend more time in open arms.

The apparatus consists of two open $(16 \times 5 \mathrm{~cm})$ and two closed arms $(16 \times 5 \times 12 \mathrm{~cm})$, and an open roof of the entire maze elevated $(25 \mathrm{~cm})$ from the floor. ${ }^{12}$ After $30 \mathrm{~min}$ of oral administration of the test drug or the standard, rats were placed at the centre of the maze, facing towards one of the open arms (Figure 1).

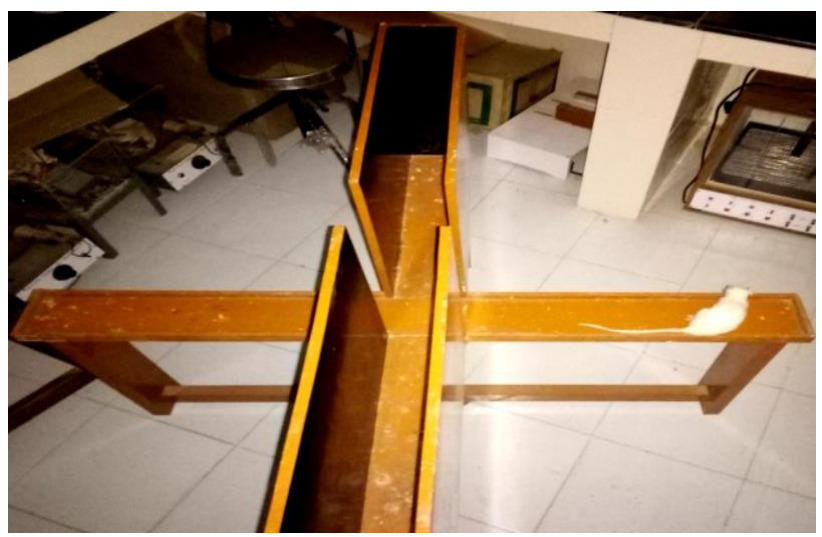

Figure 1: Elevated Plus Maze Model.

After 5min of observation the following parameters were noted: 
- The number of entries into open arm and closed arms

- Time spent in the open and enclosed arms

\section{Digital actophotometer}

\section{Principle}

A continuous beam of light from six lights will be made to fall on corresponding photoelectric cells, the photoelectric cells will get activated when an animal crossed the beam of light and thereby cuts off (crossing) the rays of light falling on it. These crossings will be counted automatically for a period of $10 \mathrm{~min}$ by the machine. The number of cuts off will be taken as a parameter of the locomotor activity of the rats. ${ }^{13}$

Rats were placed individually in the digital actophotometer $30 \mathrm{~min}$ after drug administration and number of crossings were counted for a period of $10 \mathrm{~min}$ and noted (Figure 2).

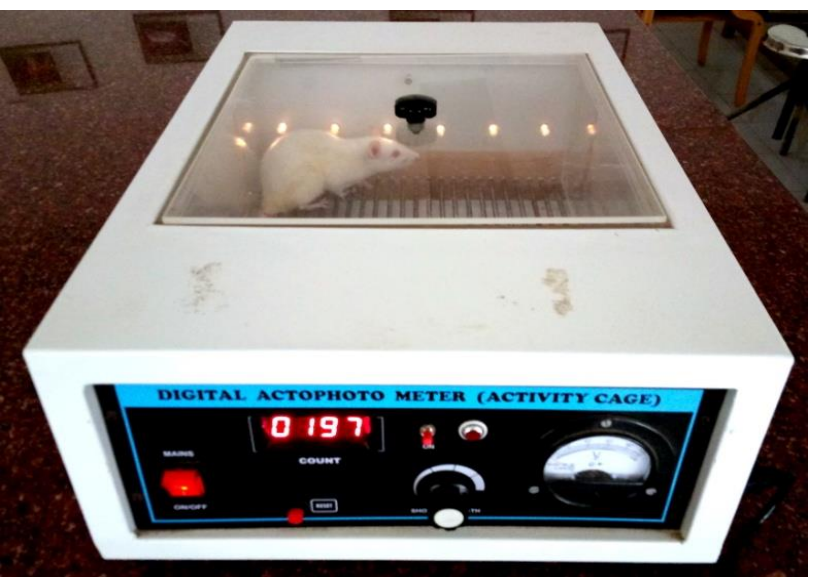

Figure 2: Digital Actophotometer Apparatus.

\section{Statistical analysis}

Statistical analysis was carried out with SPSS version 20 for windows. Mean and standard deviation were calculated for continuous variables. Comparison of five groups was done with One Way Analysis of Variance (ANOVA). Multiple comparisons were done with Post Hoc Tuckey's test.

\section{RESULTS}

\section{Elevated Plus Maze Model}

In this model efficacy was measured by an increase in the mean values of number of entries and time spent in open arm and decrease in the mean values of number of entries and time spent in closed arm of the Elevated Plus Maze apparatus. Administration of standard drug significantly showed increase in open arm activity by increase in time spent and number of entries into open arms when compared to control $(\mathrm{P}<0.05)$. Test drug Furosemide at $150 \mathrm{mg} / \mathrm{kg}$ and $200 \mathrm{mg} / \mathrm{kg}$ showed significant increase in time spent and number of entries in open arm compared to control $(\mathrm{P}<0.05)$. Even the sub threshold dose of both standard and test drug showed significant results in all the parameters when compared to control $(\mathrm{P}<0.05)$. Results are comparable to standard group in which diazepam was used (Table 1 and Table 2, Figure 3 to Figure 6).

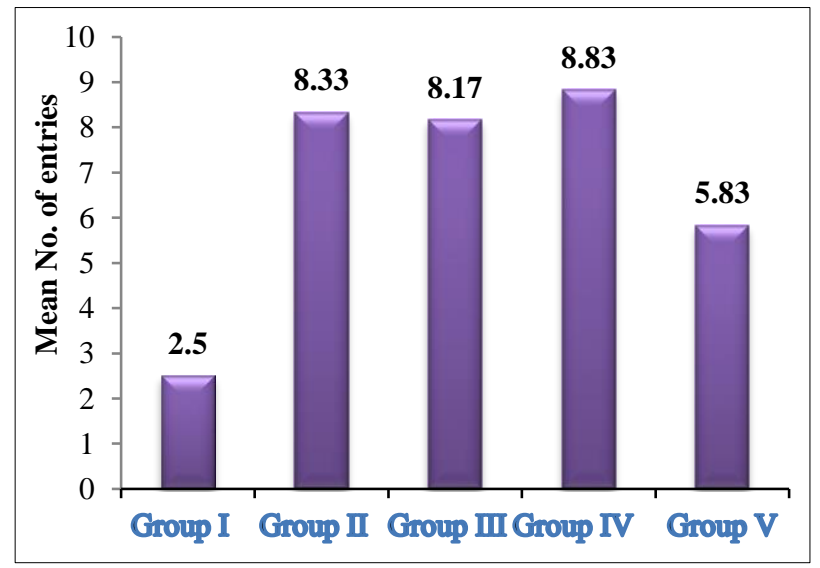

Group I- Normal saline 10ml/kg, Group II- Diazepam $2 \mathrm{mg} / \mathrm{kg}$, Group III- Furosemide150 mg/kg, Group IV- Furosemide 200mg/kg, Group V- Diazepam 1mg \& Furosemide 75 mg.

Figure 3: Mean number of entries in open arm of Elevated Plus Maze model by the groups.

Table 1: Effects of furosemide at three different doses in digital Actophotometer and Elevated Maze Plus.

\begin{tabular}{|lllllll|}
\hline Groups & & \multicolumn{2}{c}{$\begin{array}{l}\text { Actophoto meter } \\
\text { Locomotor } \\
\text { activity }\end{array}$} & \multicolumn{2}{c}{ Number of entries in } & \multicolumn{2}{l|}{ Time spent in } \\
\hline & & & Open arm & Closed arm & Open arm & Closed arm \\
\hline Group I & Control (NS) & $145.7 \pm 22.6$ & $2.5 \pm 1.05$ & $8.83 \pm 1.72$ & $69 \pm 18.79$ & $243.33 \pm 27.5$ \\
\hline Group II & Standard(DZ) & $272 \pm 47$ & $8.33 \pm 2.34$ & $5.17 \pm 1.47$ & $153 \pm 52.62$ & $157.67 \pm 70.76$ \\
\hline Group III & Furosemide $150 \mathrm{mg} / \mathrm{kg}$ & $359.8 \pm 41.7$ & $8.17 \pm 2.48$ & $5 \pm 1.26$ & $198.83 \pm 26.9$ & $105 \pm 36.41$ \\
\hline Group IV & Furosemide $200 \mathrm{mg} / \mathrm{kg}$ & $214.3 \pm 90.2$ & $8.83 \pm 1.17$ & $3.17 \pm 0.75$ & $171.33 \pm 64.28$ & $154 \pm 78.29$ \\
\hline Group V & $\begin{array}{l}\text { Furosemide } 75 \mathrm{mg} / \mathrm{kg}+ \\
\text { Diazepam } 1 \mathrm{mg} / \mathrm{kg}\end{array}$ & $290.7 \pm 123$ & $5.83 \pm 0.75$ & $2 \pm 1.1$ & $131 \pm 17.93$ & $102.17 \pm 59.1$ \\
\hline
\end{tabular}

Results are expressed as Mean value \pm SD (standard deviation) 
Table 2: Tukey's Post HOC multiple comparison test between the groups (control, standard and test groups) for locomotor activity in Actophotometer Model and number of entries and time spent in elevated Plus Maze Model.

\begin{tabular}{|c|c|c|c|c|c|}
\hline & Actophoto meter & Elevated p & & & \\
\hline & Locomotor activity & Number of & & Time spen & \\
\hline & & Open arm & Closed arm & Open arm & Closed arm \\
\hline I VS II & ${ }^{*} \mathrm{P}<0.05$ & $* \mathrm{P}<0.000$ & $* \mathrm{P}<0.000$ & $* \mathrm{P}<0.02$ & $* \mathrm{P}<0.02$ \\
\hline I VS III & ${ }^{*} \mathrm{P}<0.000$ & $* \mathrm{P}<0.000$ & $* \mathrm{P}<0.000$ & $* \mathrm{P}<0.000$ & $* \mathrm{P}<0.003$ \\
\hline I VS IV & $* \mathrm{P}<0.05$ & $* \mathrm{P}<0.000$ & $* \mathrm{P}<0.000$ & $* \mathrm{P}<0.002$ & $* \mathrm{P}<0.08$ \\
\hline I VS V & $* \mathrm{P}<0.01$ & $* \mathrm{P}<0.01$ & $* \mathrm{P}<0.000$ & $* \mathrm{P}<0.09$ & $* \mathrm{P}<0.002$ \\
\hline II VS III & 0.276 & 1.000 & 0.990 & 0.319 & 0.523 \\
\hline II VS IV & 0.669 & 0.986 & 0.090 & 0.934 & 1.000 \\
\hline II VS V & 0.990 & 0.116 & $* \mathrm{P}<0.002$ & 0.889 & 0.475 \\
\hline III VS IV & $* \mathrm{P}<0.01$ & 0.960 & 0.139 & 0.768 & 0.592 \\
\hline III VS V & 0.508 & 0.160 & $* \mathrm{P}<0.004$ & $* \mathrm{P}<0.05$ & 1.000 \\
\hline IV VS V & 0.409 & $* \mathrm{P}<0.04$ & 0.540 & 0.443 & 0.540 \\
\hline
\end{tabular}

*P value less than 0.05 is significant

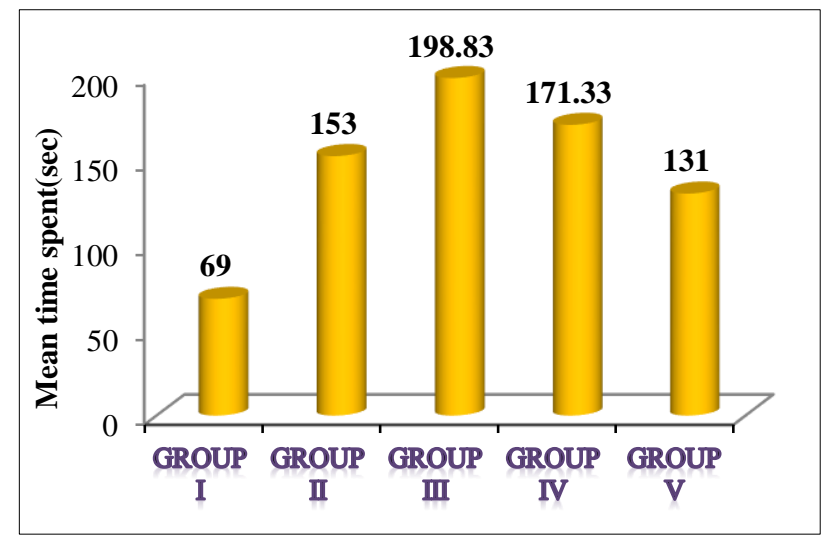

Group I- Normal saline 10ml/kg, Group II- Diazepam 2mg/kg, Group III- Furosemide150mg/kg, Group IV- Furosemide 200mg/kg, Group V- Diazepam 1mg and Furosemide 75mg.

Figure 4: Mean time spent in open arm of Elevated Plus Maze model by the groups.

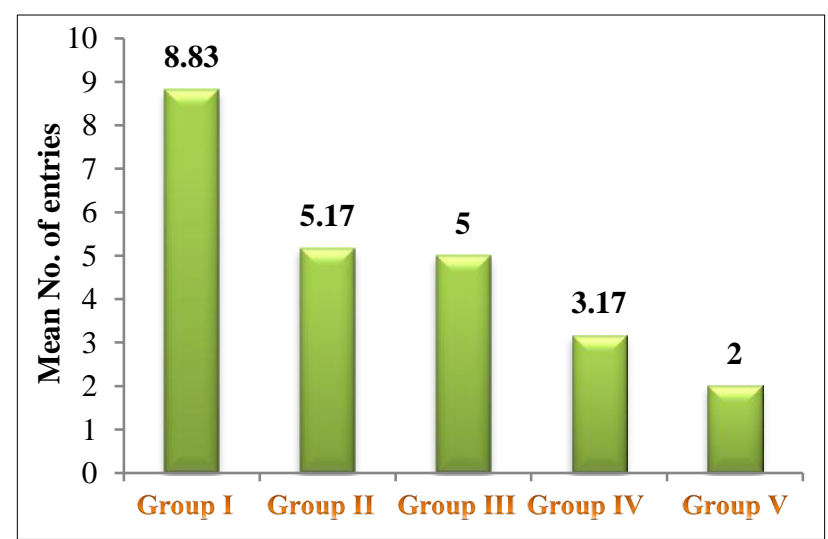

Group I- Normal saline 10ml/kg, Group II- Diazepam 2mg/kg, Group III- Furosemide150 mg/kg, Group IV- Furosemide 200mg/kg, Group V- Diazepam 1mg and Furosemide 75mg.

Figure 5: Mean number of entries in closed arm of Elevated Plus Maze model by the groups.

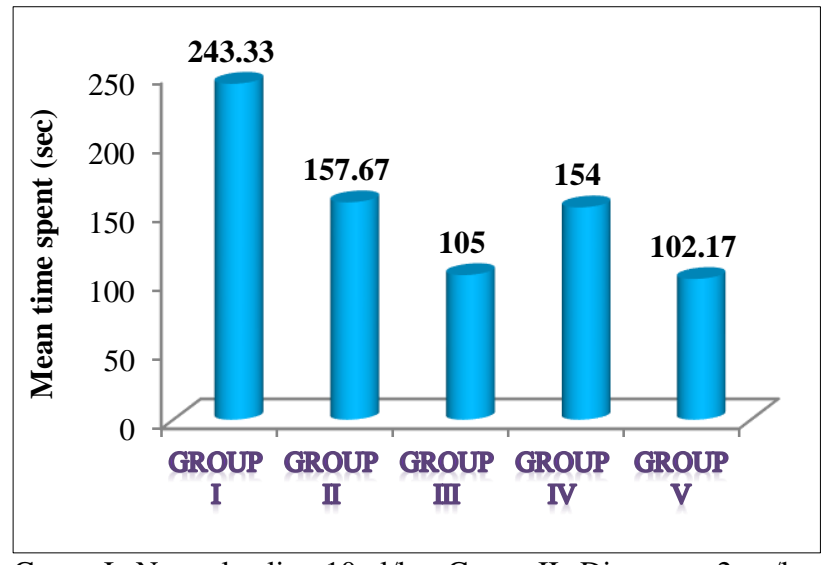

Group I- Normal saline 10ml/kg, Group II- Diazepam 2mg/kg, Group III- Furosemide150 mg/kg, Group IV- Furosemide 200mg/kg, Group V- Diazepam 1mg and Furosemide 75mg.

Figure 6: Mean time spent in closed arm of Elevated Plus Maze model by the groups.

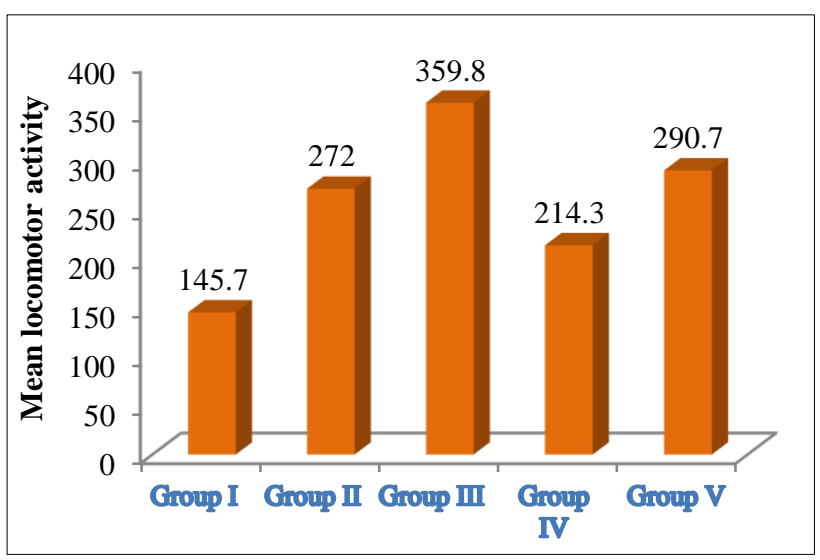

Group I- Normal saline 10ml/kg, Group II- Diazepam $2 \mathrm{mg} / \mathrm{kg}$, Group III- Furosemide 150mg/kg, Group IV- Furosemide $200 \mathrm{mg} / \mathrm{kg}$, Group V- Diazepam 1mg and Furosemide 75mg.

Figure 7: Mean locomotor activity in Actophotometer model by the groups. 


\section{Digital Actophotometer Model}

In this model efficacy was assessed by decrease in the mean values of parameter i.e. locomotor activity in Digital Actophotometer apparatus. Diazepam significantly reduced locomotor activity compared to control $(\mathrm{P}<0.05)$. Furosemide at $75 \mathrm{mg} / \mathrm{kg}, 150 \mathrm{mg} / \mathrm{kg}$ and $200 \mathrm{mg} / \mathrm{kg}$ showed significant decrease in locomotor activity when compared to control $(\mathrm{P}<0.05)$. In this model furosemide has shown dose dependent decrease in locomotor activity. Results are comparable to standard diazepam treated group (Table 1 and Table 2, Figure 7).

\section{DISCUSSION}

According to recent reports anxiety burdens every 1 in 13 individuals globally and therefore offers an important challenge in the treatment as well opens doors in the fields of drug development research. ${ }^{11}$ In this study, Furosemide showed anxiolytic effect in elevated plus maze and digital actophotometer.

Furosemide is a known diuretic and thought to affect $\mathrm{GABA}_{\mathrm{A}}$ mediated signalling in brain through their antagonism of cation-chloride contransport, which might be responsible for its anxiolytic action. ${ }^{3}$

Specifically, furosemide antagonize the $\mathrm{Na}^{+}-\mathrm{K}^{+}-2 \mathrm{Cl}^{-}$ (NKCC1) cotransporter that is present on both neurons and glial cells, and the neuron-specific $\mathrm{K}^{+}-\mathrm{Cl}^{-}$(KCC2) cotransporter. ${ }^{10,11}$ Furosemide has significantly greater affinity for $\mathrm{NKCC} 1$ over $\mathrm{KCC} 2 .^{10}$ Hyperpolarizing inhibitory postsynaptic potentials in neurons are generated by the influx of anions $\left(\mathrm{HCO}_{3}{ }^{-}\right.$and $\left.\mathrm{Cl}^{-}\right)$down their electrochemical gradients. Since $\mathrm{GABA}_{\mathrm{A}}$ receptormediated current is determined, in part, by the difference between the equilibrium potential for $\mathrm{Cl}^{-}$and the neuronal membrane potential, preferential antagonism of NKCC1 with a loop diuretic would be expected to cause a hyperpolarizing shift in the GABA reversal potential, enhancing $\mathrm{GABA}_{\mathrm{A}}$ synaptic signalling. This effect can be particularly important in view of recent work showing the dominant role that NKCC1 plays at the axon initial segment of principal neurons. Since loop diuretics are antagonists of the NKCC1 and KCC2 cotransporters, these results implicate the cation-chloride cotransport system as possible molecular mechanism involved in anxiety, and as novel pharmacological target for the development of anxiolytics. $^{14}$

Krystal et al showed loop diuretics have anxiolytic effect in rat models of conditioned anxiety. ${ }^{3}$ Since only one dose of furosemide was taken, we cannot exclude the possibility of this drug having anxiolytic activity in unconditioned anxiety models so further studies are required in this field. ${ }^{14}$

In the present study, Elevated Plus Maze and Digital Actophotometer were used for evaluation.
Both the models showed anxiolytic effect of furosemide at 150 and $200 \mathrm{mg} / \mathrm{kg}$ and also potentiation effect was seen when sub threshold dose $(75 \mathrm{mg} / \mathrm{kg})$ of furosemide was given in combination with sub threshold dose of diazepam.

Furosemide has advantage over other agents as it provides immediate onset of action (unlike SSRIs, SNRIs) and without sedation, cognitive impairment, and the abuse potential of benzodiazepines. ${ }^{3}$

\section{CONCLUSION}

From the above observations we can conclude that Furosemide has anxiolytic activity at three different doses $(75,150$ and $200 \mathrm{mg} / \mathrm{kg}$ ) which is comparable with the standard drug diazepam.

The anxiolytic property of furosemide will enhance its therapeutic utility. Hence with further clinical studies furosemide can be effectively used in cardiovascular condition like hypertension and congestive cardiac failure which is often associated with anxiety.

\section{ACKNOWLEDGEMENTS}

Authors would like to thank the Post graduate students and Professors of Department of Pharmacology. Authors would also like to extend my thanks to the animal house and Biostatistician of JJMMC, Davangere, India.

\section{Funding: No funding sources \\ Conflict of interest: None declared}

Ethical approval: The study was approved by the Institutional Ethics Committee of JJM Medical College (Committee for the Purpose of Control and Supervision of Experiments on Animals, India Ref No. JJMMC/IAEC/072016)

\section{REFERENCES}

1. Remes O, Brayne C, Linde R, Lafortune L. A systematic review of reviews on the prevalence of anxiety disorders in adult populations. Brain and behavior. 2016 Jul 1;6(7).

2. American Psycology Association [Internet] [Cited 12/01/17]. Available at: http://www.apa.org/topic/anxiety.

3. Krystal A, Sutherland J, Hochman W. Loop diuretics have anxiolytic effects in rat models of conditioned anxiety. PLoS ONE. 2012 April;7(4):e35417.

4. Mahendra P, Bisht S. Anti-anxiety activity of Coriandrum sativum assessed using different experimental anxiety models. Indian $\mathrm{J}$ Pharmacol. 2011;43(5):574-7.

5. Lydiard RB. The role of gaba in anxiety disorders. J Clin Psychiatry. 2003;64(3):21-7.

6. Russell JM. Sodium-potassium-chloride cotransport. Physiological Reviews. 2000;80:211-76. 
7. Blaesse P, Airaksinen MS, Rivera C, Kaila K. Cationchloride cotransporters and neuronal function. Neuron. 2009;61:820-38.

8. Chen H, Sun D. The role of Na-K-Cl co-transporter in cerebral ischemia. Neurol Res. 2005;27:280-6.

9. Jayakumar AR, Norenberg MD. The Na-K-Cl cotransporter in astrocyte swelling. Metab Brain Dis. 2010;25:31-8.

10. MacVicar BA, Feighan D, Brown A, Ransom B. Intrinsic optical signals in the rat optic nerve: role for $\mathrm{K}(+)$ uptake via NKCC1 and swelling of astrocytes. Glia. 2002;37:114-23.

11. Fernandez-robles C, Stern TA, Caro MA, Huffman JC; Pharmacological aspects. Dialogues Clin. Neurosci. 2011;13:109-25.
12. Kulkarni SK. Delhi: Vallabh Prakashan; Handbook of Experimental Pharmacology; 1999:135-137.

13. Halemani D. Evaluation of anti-anxiety activity of methanol extract of aegle maemelos (Bael fruit tree) leaves in rats. IOSR-JDMS. Sept 2015;14(9):01-5.

14. Whiteford, Harvey A, Degenhardt L, Jurgem R, Baxter AJ. Global burden of disease attributable to mental and substance use disorders: findings from the Global Burden of Disease Study 2010. Lancet. 2013;382(9904):1575-86.

Cite this article as: Goyal M, Jyothi $\mathrm{CH}$, Damodar RH. Evaluation of anxiolytic effect of furosemide in Albino rats. Int J Basic Clin Pharmacol 2018;7:33742. 